\title{
Group Differences Between Counselor Education Doctoral Students' Number of Fieldwork Experiences and Teaching Self-Efficacy
}

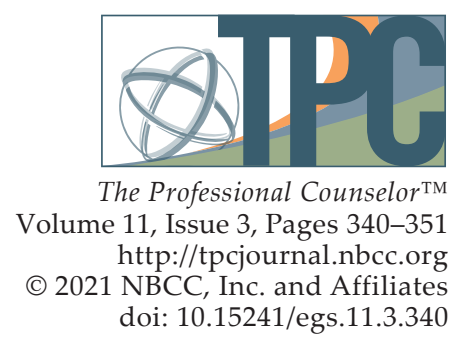

Eric G. Suddeath, Eric R. Baltrinic, Heather J. Fye, Ksenia Zhbanova, Suzanne M. Dugger, Sumedha Therthani

This study examined differences in 149 counselor education doctoral students' self-efficacy toward teaching related to their number of experiences with fieldwork in teaching (FiT). Results showed counselor education doctoral students began FiT experiences with high levels of self-efficacy, which decreased after one to two FiT experiences, increased slightly after three to four FiT experiences, and increased significantly after five or more FiT experiences. We discuss implications for how counselor education doctoral programs can implement and supervise FiT experiences as part of their teaching preparation practices. Finally, we identify limitations of the study and offer future research suggestions for investigating FiT experiences in counselor education.

Keywords: teaching preparation, self-efficacy, fieldwork in teaching, counselor education, doctoral students

Counselor education doctoral students (CEDS) need to engage in actual teaching experiences as part of their teaching preparation (Baltrinic et al., 2016; Baltrinic \& Suddeath, 2020a; Barrio Minton, 2020; Swank \& Houseknecht, 2019), yet inconsistencies remain in defining what constitutes actual teaching experience. Fortunately, several researchers (e.g., Association for Counselor Education and Supervision [ACES], 2016; Hunt \& Weber Gilmore, 2011; Suddeath et al., 2020) have identified examples of teaching experiences, which we aggregated and defined as fieldwork in teaching (FiT). FiT includes the (a) presence of experiential training components such as co-teaching, formal teaching practicums and/or internships, and teaching assistantships (ACES, 2016); (b) variance in amount of responsibility granted to CEDS (Baltrinic et al., 2016; Barrio Minton \& Price, 2015; Orr et al., 2008; Suddeath et al., 2020); and (c) use of regular supervision of teaching (Baltrinic \& Suddeath, 2020a; Suddeath et al., 2020). Findings from several studies suggested that a lack of FiT experience can thwart CEDS' teaching competency development (Swank \& Houseknecht, 2019), contribute to CEDS' feelings of insufficient preparation for future teaching roles (Davis et al., 2006), create unnecessary feelings of stress and burnout for first-year faculty (Magnuson et al., 2004), and lead to feelings of inadequacy among new counselor educators (Waalkes et al., 2018). Counselor education (CE) researchers reference FiT experiences (Suddeath et al., 2020) among a variety of teaching preparation practices, such as co-teaching (Baltrinic et al., 2016), supervision of teaching (Baltrinic \& Suddeath, 2020a), collaborative teaching teams (CTT; Orr et al., 2008), teaching practicums (Baltrinic \& Suddeath, 2020a; Hall \& Hulse, 2010), teaching internships (Hunt \& Weber Gilmore, 2011), teaching to peers within teaching instruction courses (Baltrinic \& Suddeath, 2020b; Elliot et al., 2019), and instructor of record (IOR) experiences (Moore, 2019).

Participants across studies emphasized the importance of including FiT experiences within teaching preparation practices. Both CEDS and new faculty members reported that engaging in actual teaching

Eric G. Suddeath, PhD, LPC-S (MS), is an associate professor at Denver Seminary. Eric R. Baltrinic, PhD, LPCC-S (OH), is an assistant professor at the University of Alabama. Heather J. Fye, PhD, NCC, LPC (OH), is an assistant professor at the University of Alabama. Ksenia Zhbanova, EdD, is an assistant professor at Mississippi State University-Meridian. Suzanne M. Dugger, EdD, NCC, ACS, LPC (MI), SC (MI, FL), is a professor and department chair at Florida Gulf Coast University. Sumedha Therthani, PhD, NCC, is an assistant professor at Mississippi State University. Correspondence may be addressed to Eric G. Suddeath, 6399 South Santa Fe Drive, Littleton, C0 80120, ericsuddeath@gmail.com. 
(e.g., FiT) as part of their teaching preparation buffered against lower teaching self-efficacy (Baltrinic \& Suddeath, 2020a; Elliot et al., 2019; Suddeath et al., 2020). These findings are important because high levels of teaching self-efficacy are associated with increased student engagement (Gibson \& Dembo, 1984), positive learning outcomes (Goddard et al., 2000), greater job satisfaction, reduced stress and emotional exhaustion, longevity in the profession (Klassen \& Chiu, 2010; Skaalvik \& Skaalvik, 2014), and flexibility and persistence during perceived setbacks in the classroom (Elliot et al., 2019; Gibson \& Dembo, 1984).

\section{FiT Within Counselor Education}

Existing CE teaching literature supports the presence and use of FiT within a larger framework of teaching preparation. Despite existing findings, variability exists in how FiT is both conceptualized and implemented among doctoral programs and in how doctoral students specifically engage in FiT during their program training. Current literature supporting FiT suggests several themes, which are outlined below, to support our gap in understanding of (a) whether FiT experiences are required, (b) the number of FiT experiences in which CEDS participate, (c) the level and type of student responsibility, and (d) the supervision and mentoring practices that support student autonomy within FiT experiences (e.g., Baltrinic et al., 2016, 2018; Orr et al., 2008; Suddeath et al., 2020).

\section{Teaching Internships and Fieldwork}

Teaching internships are curricular teaching experiences in which CEDS co-teach (most often) a master's-level course with a program faculty member or with peers while receiving regular supervision (Hunt \& Weber Gilmore, 2011). These experiences are offered concurrently with pedagogy or adult learning courses (Hunt \& Weber Gilmore, 2011) or after taking a course (Waalkes et al., 2018). Teaching internships typically include group supervision (Baltrinic \& Suddeath, 2020a), though the frequency and structure of supervision varies greatly (Suddeath et al., 2020). Participants in Baltrinic and Suddeath's (2020a) study reported that teaching practicum and internship experiences are often included alongside multiple types of internships (e.g., clinical, supervision, and research), which led to less time to process their own teaching experiences. The level of responsibility within FiT experiences also varies. Specifically, CEDS may take on minor roles, including "observing faculty members' teaching and ... contributing anecdotes from their counseling experiences to class discussion" (Baltrinic et al., 2016, p. 38), providing the occasional lecture or facilitating a class discussion, or engaging in administrative duties such as grading and making copies of course materials (Hall \& Hulse, 2010; Orr et al., 2008). Research also suggests that CEDS may share the responsibility for designing, delivering, and evaluating the course (Baltrinic et al., 2016). Finally, CEDS may take on sole/primary responsibility, including the design and delivery of all aspects of a course (Orr et al., 2008).

\section{Co-Teaching and CTT}

It is important to distinguish formal curricular FiT experiences such as teaching practicums and internships from informal co-curricular co-teaching experiences. For example, Baltrinic et al. (2016) identified co-teaching as a process of pairing experienced faculty members with CEDS for the purpose of increasing their knowledge and skill in teaching through supervised teaching experiences. CEDS often receive more individual supervision and mentoring in these informal experiences based on individual agreements between the CEDS and willing faculty members (Baltrinic \& Suddeath, 2020a). One example of a formal co-teaching experience (i.e., CTT) comes from Orr et al. (2008). In this model, CEDS initially observe a course or courses while occasionally presenting on course topics. The CEDS then take the lead for designing and delivering the course while under the direct supervision (both live in the classroom and post-instruction) of counseling faculty members. 


\section{Instructor of Record}

At times, CEDS have the opportunity to teach a course as the sole instructor, what Moore (2019) and Orr et al. (2008) defined as an instructor of record (IOR). In these cases, IORs are fully responsible for the delivery and evaluation components of the course, including determining students' final grades. CEDS may take on IOR roles after completing a progression of teaching responsibilities over time under supervision (Moore, 2019; Orr et al., 2008). In some instances, CEDS who serve as IORs are hired as adjunct or part-time instructors (Hebbani \& Hendrix, 2014). Ultimately, it seems like a respectable outcome of teaching preparation in general, and specifically FiT, to prepare CEDS to transition into IOR roles. CEDS who attain the responsibility of IOR for one class are partially prepared for managing a larger teaching workload as a faculty member (i.e., teaching three classes per semester; 3:3 load).

\section{Impact of Teaching Fieldwork}

Overall, researchers identified FiT experiences as essential for strengthening CEDS' feelings of preparedness to teach (Hall \& Hulse, 2010), for fostering their teaching identities (Limberg et al., 2013; Waalkes et al., 2018), and for supporting their perceived confidence and competence to teach (Baltrinic et al., 2016; Orr et al., 2008). CE research suggests several factors that contribute to the relative success of the FiT experience. For example, Hall and Hulse (2010) found fieldwork most helpful when the experiences mimicked the actual roles and responsibilities of a counselor educator rather than guest lecturing or providing the occasional lecture. Participants in Hunt and Weber Gilmore's (2011) study echoed this sentiment, emphasizing the importance of experiences related to the design, delivery, and evaluation of a course. Important experiences included developing or co-developing course curriculum and materials (e.g., exams, syllabi, grading rubrics), facilitating class discussions, lecturing, and evaluating student learning. Additionally, these experiences helped CEDS to translate adult learning theories and pedagogy into teaching practice, which is an essential process for strengthening CEDS' teaching identity (Hunt \& Weber Gilmore, 2011; Waalkes et al., 2018). CE literature also points to the importance of providing CEDS with multiple supervised, developmentally structured (Orr et al., 2008) FiT experiences to increase levels of autonomy and responsibility with teaching and related duties (Baltrinic et al., 2016; Baltrinic \& Suddeath, 2020a; Orr et al., 2008). Hall and Hulse found that teaching a course from start to finish contributed most to CEDS' perceived preparedness to teach. The CTT approach (Orr et al., 2008) is one example of how CE programs developmentally structure FiT experiences.

Research affirms the integration of supervision across CEDS' FiT experiences (e.g., Baltrinic \& Suddeath, 2020a; Elliot et al., 2019; Hunt \& Weber Gilmore, 2011). CEDS receive the essential support, feedback, and oversight during supervision that helps them make sense of teaching experiences and identify gaps in teaching knowledge and skills (Waalkes et al., 2018). Research suggests that structured, weekly supervision is most helpful in strengthening CEDS' perceived confidence (Suddeath et al., 2020) and competence in teaching (Orr et al., 2008). Baltrinic and Suddeath (2020a) and Elliot et al. (2019) also identified supervision of FiT as an essential experience for buffering against CEDS' fear and anxiety associated with initial teaching experiences. Both studies found that supervision led to fewer feelings of discouragement and perceived failures related to teaching, as well as increased confidence in their capabilities, even when teaching unfamiliar material. Elliot et al. attributed this to supervisors normalizing CEDS' teaching experiences as a part of the developmental process, which helped them to push through the initial discomfort and fear in teaching and reframe it as an opportunity for growth.

\section{Self-Efficacy Toward Teaching}

Broadly defined, self-efficacy is the future-oriented "belief in one's capabilities to organize and execute the courses of action required to produce given attainments" (Bandura, 1997, p. 3). Applied to teaching, it is confidence in one's ability to select and utilize appropriate teaching behaviors effectively 
to accomplish a specific teaching task (Tschannen-Moran et al., 1998). Research in CE has outlined the importance of teaching self-efficacy on CEDS' teaching development, including its relationship to a strengthened sense of identity as a counselor educator (Limberg et al., 2013); increased autonomy in the classroom (Baltrinic et al., 2016); greater flexibility in the application of learning theory; increased focus on the teaching experience and students' learning needs instead of one's own anxiety; and pushing through feelings of fear, self-doubt, and incompetence associated with initial teaching experiences (Elliot et al., 2019). Previous research affirms FiT as a significant predictor of teaching self-efficacy (Olguin, 2004; Suddeath et al., 2020; Tollerud, 1990). Recently, Suddeath et al. (2020) found that students participating in more FiT experiences also reported higher levels of teaching self-efficacy.

\section{Purpose of the Present Study}

In general, research supports the benefits of FiT experiences (e.g., increased self-efficacy, strengthened teaching identity, and a better supported transition to the professoriate) and ways in which FiT experiences (e.g., multiple, developmentally structured, supervised) should be provided as part of CE programs' teaching preparation practices. Past and current research supports a general trend regarding the relationship between $\mathrm{CE}$ teaching preparation, including FiT experiences, and teaching self-efficacy (Suddeath et al., 2020). However, we know very little about how the number of FiT experiences, specifically, differentially impacts CEDS' teaching self-efficacy. To address this gap, we examined the relationship between the number of CEDS' FiT experiences and their reported self-efficacy in teaching. Accordingly, we proceeded in the present study guided by the following research question: How does CEDS' self-efficacy toward teaching differ depending on amount of FiT experience gained (i.e., no experience in teaching, one to two experiences, three to four experiences, five or more experiences)? This research question was prompted by the work of Olguin (2004) and Tollerud (1990), who investigated CEDS' reported differences in self-efficacy toward teaching across similarly grouped teaching experiences. We wanted to better understand the impact of FiT experiences on CEDS' teaching self-efficacy given the prevalence of teaching preparation practices used in CE doctoral programs.

\section{Method}

\section{Participant Characteristics}

A total of 171 individuals responded to the survey. Participants who did not finish the survey or did not satisfy inclusionary criteria (i.e., 18 years or older and currently enrolled in a doctoral-level CACREP-accredited CE program) were excluded from the sample, leaving 149 usable surveys. Of these 149 participants, 117 (79\%) were female and 32 (21\%) were male. CEDS ranged in age from 23-59 years with a mean age of 34.73. Regarding race, 116 CEDS (73\%) identified as White, 25 (17\%) as Black, six $(4 \%)$ as Asian, one $(0.7 \%)$ as American Indian or Alaskan Native, and one $(0.7 \%)$ as multiracial. Fifteen participants (10\%) indicated a Hispanic/Latino ethnicity. Of the 149 participants, 108 provided their geographic region, with $59(39 \%)$ reportedly living in the Southern United States, $32(21 \%)$ in the Midwest, $10(7 \%)$ in the West, and eight (5\%) in the Northeast. Participants' time enrolled in a CE program ranged from zero semesters (i.e., they were in their first semester) to 16 semesters $(M=6.20)$.

\section{Sampling Procedures}

After obtaining IRB approval, we recruited participants using two convenience sampling strategies. First, we sent counselor education and supervision doctoral program liaisons working in CACREP-accredited universities a pre-notification email (Creswell \& Guetterman, 2019), which contained an explanation and rationale for this proposed study; a statement about informed consent and approval; a link to the composite survey, which included the demographic questionnaire; a 
question regarding FiT experiences; the Self-Efficacy Toward Teaching Inventory (SETI; Tollerud, 1990); and a request to forward the recruitment email (which was copied below the pre-notification text) to all eligible doctoral students. Next, we solicited CEDS' participation through the Counselor Education and Supervision Network Listserv (CESNET-L), which is a professional listserv of counselors, counselor educators, and master's- and doctoral-level CE students. We sent two follow-up participation requests, one through CESNET- $L$ and the other to doctoral program liaisons (Creswell \& Guetterman, 2019) to improve response rates. We further incentivized participation through offering participants a chance to win one of five $\$ 20$ gift cards through an optional drawing.

\section{Data Collection}

We collected all research data through the survey software Qualtrics. CEDS who agreed to participate clicked the survey link at the bottom of the recruitment email, which took them to an informed consent information and agreement page. Participants meeting inclusionary criteria then completed the basic demographic questionnaire, a question regarding their FiT experiences, and the SETI.

\section{Measures}

We used a composite survey that included a demographic questionnaire, a question regarding FiT experiences, and a modified version of the SETI. To strengthen the content validity of the composite survey, we selected a panel of three nationally recognized experts known for their research on CEDS teaching preparation to provide feedback on the survey items' "relevance, representativeness, specificity, and clarity" as well as "suggested additions, deletions, and modifications" of items (Haynes et al., 1995, pp. 244, 247). We incorporated feedback from these experts and then piloted the survey using seven recent graduates (i.e., within 4 years) from CACREP-accredited CE doctoral programs. Feedback from the pilot group influenced final modifications of the survey.

\section{Demographic Questionnaire}

The demographic questionnaire included questions regarding CEDS' sex, age, race/ethnicity, geographic region, and time in program. Example items included: "Age in years?," "What is your racial background?," "Are you Hispanic or Latino?," and "In which state do you live?"

\section{Fieldwork Question}

We used CE literature (e.g., ACES, 2016; Baltrinic et al., 2016; Orr et al., 2008) as a guide for defining and constructing the item to inquire about CEDS' FiT experiences, which served as the independent variable in this study. In the survey, FiT was defined as teaching experiences within the context of formal teaching internships, informal co-teaching opportunities, graduate teaching assistantships, or independent teaching of graduate or undergraduate courses. Using this definition, participants then indicated "the total number of course sections they had taught or cotaught." Following Tollerud (1990) and Olguin (2004), we also grouped participants' FiT experiences into four groups (i.e., no experience, one to two experiences, three to four experiences, five or more experiences) to extend their findings.

\section{Self-Efficacy Toward Teaching}

To measure self-efficacy toward teaching, the dependent variable in this study, we used a modified version of the SETI. The original SETI is a 35-item self-report measure in which participants indicate their confidence to implement specific teaching skills and behaviors in five teaching domains within CE: course preparation, instructor behavior, materials, evaluation and examination, and clinical skills training. We modified the SETI according to the expert panel's recommendations, which included creating 12 new items related to using technology in the classroom and teaching adult learners, as well as modifying the wording of several items to match CACREP 2016 teaching standards. This modified 
version of the SETI contained 47 items. Examples of new and modified items in each of the domains included: "Incorporate models of adult learning" (Course Preparation), "Attend to issues of social and cultural diversity" (Instructor Behavior), "Utilize technological resources to enhance learning" (Materials), "Construct multiple choice exams" (Evaluation and Examination), and "Provide supportive feedback for counseling skills" (Clinical Skills Training). The original SETI produced a Cronbach's alpha of .94, suggesting strong internal consistency. Other researchers using the SETI reported similar findings regarding the internal consistency including Richardson and Miller (2011), who reported alphas of .96, and Prieto et al. (2007), who reported alphas of .94. The internal consistency for the modified SETI in this study produced a Cronbach's alpha of .97, also suggesting strong internal consistency of items.

\section{Design}

This study used a cross-sectional survey design to investigate group differences in CEDS' self-efficacy toward teaching by how many FiT experiences students had acquired (Creswell \& Guetterman, 2019). Cross-sectional research allows researchers to better understand current beliefs, attitudes, or practices at a single point in time for a target population. This approach allowed us to gather information related to current FiT trends and teaching self-efficacy beliefs across CE doctoral programs.

\section{Data Preparation and Analytic Strategy}

After receiving the participant responses, we coded and entered them into SPSS (Version 27) for conducting all descriptive and inferential statistical analyses. Based upon previous research by Tollerud (1990) and Olguin (2004), we then grouped participants according to the number of experiences reported: no fieldwork experience, one to two experiences, three to four experiences, and five or more experiences. We then ran a one-way ANOVA to determine if CEDS' self-efficacy significantly $(p<.05)$ differed according to the number of teaching experiences accrued, followed by post hoc analyses to determine which groups differed significantly.

\section{Results}

We sought to determine whether CEDS with no experience in teaching, one to two experiences, three to four experiences, or five or more experiences differed in terms of their self-efficacy toward teaching scores. Overall, individuals in this study who reported no FiT experience indicated higher mean SETI scores $(n=10, M=161.00, S D=16.19)$ than those with one to two fieldwork experiences $(n=37$, $\mathrm{M}=145.59, S D=21.41)$ and three to four fieldwork experiences $(n=32, M=148.41, S D=20.90)$. Once participants accumulated five or more fieldwork experiences $(n=70, M=161.06, S D=19.17)$, the mean SETI score rose above that of those with no, one to two, and three to four FiT experiences. The results also indicated an overall mean of 5.51 FiT experiences $(S D=4.63$, range $=0-21)$.

As shown in Table 1, a one-way ANOVA revealed a statistically significant difference between the scores of the four FiT groups, $F(3,145)=6.321, p<.001$, and a medium large effect size $\left(\eta^{2}=.12\right.$; Cohen, 1992). Levene's test revealed no violation of homogeneity of variance $(p=.763)$. A post hoc Tukey Honest Significant Difference test allowed for a more detailed understanding of which groups significantly differed. Findings revealed a statistically significant difference between the mean SETI scores for those with one to two fieldwork experiences and five or more experiences (mean difference $=-15.46, p=.001$ ) and for those with three to four and five or more experiences (mean difference $=-12.65, p=.018$ ). There was no significant difference between those with no FiT experience and those with five or more experiences, and in fact, these groups had nearly identical mean scores (i.e., 161.00 and 161.06, respectively). Although the drop is not significant, there is a mean difference of 15.40 from no FiT 
experience to one to two experiences. These results suggest that perceived confidence in teaching, as measured by the SETI, began high, dropped off after one to two experiences, slightly rose after three to four, and then increased significantly from 148.41 to 161.06 after five or more experiences, returning to pre-FiT levels.

\section{Table 1}

Means, Standard Deviations, and One-Way Analysis of Variance for Study Variables

\begin{tabular}{|c|c|c|c|c|c|c|c|c|c|c|}
\hline \multirow[t]{2}{*}{ Measure } & \multicolumn{2}{|c|}{ No FiT } & \multicolumn{2}{|c|}{ 1-2 FiT } & \multicolumn{2}{|c|}{ 3-4 FiT } & \multicolumn{2}{|c|}{5 or More FiT } & \multirow{2}{*}{$F(3,145)$} & \multirow{2}{*}{$\eta^{2}$} \\
\hline & $M$ & $S D$ & $M$ & $S D$ & $M$ & $S D$ & $M$ & $S D$ & & \\
\hline SETI & 161.00 & 16.19 & 145.59 & 21.41 & 148.41 & 20.90 & 161.06 & 19.17 & $6.321^{*}$ & .12 \\
\hline
\end{tabular}

Note. SETI = Self-Efficacy Toward Teaching Inventory; FiT = field work in teaching. ${ }^{*} p<.001$.

\section{Discussion}

The purpose of this study was to investigate whether CEDS with no experience in teaching, one to two experiences, three to four experiences, or five or more experiences differed in terms of their selfefficacy toward teaching scores. Overall, one-way ANOVA results revealed a significant difference in SETI scores by FiT experiences. Post hoc analyses revealed an initial substantial drop from no experience to one to two experiences and a significant increase in self-efficacy toward teaching between one to two FiT experiences and five or more experiences as well as between three to four FiT experiences and five or more experiences.

The CE literature supports the general trend observed in this study, that as the number of FiT experiences increases, so does CEDS' teaching self-efficacy (e.g., Baltrinic \& Suddeath 2020a; Hunt \& Weber Gilmore, 2011; Suddeath et al., 2020). Many authors have articulated the importance of multiple fieldwork experiences for preparing CEDS to confidently transition to the professoriate (e.g., Hall \& Hulse, 2010; Orr et al., 2008). Participants in a study by Hunt and Weber Gilmore (2011) identified engagement in multiple supervised teaching opportunities that mimicked the actual teaching responsibilities required of a counselor educator as particularly helpful. Tollerud (1990) and Olguin (2004) found that the more teaching experiences individuals acquired during their doctoral programs, the higher their self-efficacy toward teaching. Encouragingly, nearly half of CEDS in this study (47\%) indicated that participating in five or more teaching experiences increased their teaching self-efficacy. This increase in teaching self-efficacy may be due to expanded use of teaching preparation practices within CE doctoral programs (ACES, 2016).

Participants in the current study reported an initial drop in self-efficacy after their initial FiT experiences, which warrants explanation. Specifically, the initial drop in CEDS' self-efficacy could be due to discrepancies between their estimation of teaching ability and their actual capability, further supporting the idea of including actual FiT earlier in teaching preparation practices, albeit titrated in complexity. Though one might assume that as participants acquired additional teaching experience their SETI scores would have increased, the initial pattern from no experience to one 
to two FiT experiences did not support this. However, self-efficacy is not necessarily a measure of actual capability, but rather one's confidence to engage in certain behaviors to achieve a certain task (Bandura, 1997). It is plausible that participants may have initially overestimated their own abilities and level of control over the new complex task of teaching, which may explain the initial drop in selfefficacy among participants. For participants lacking FiT experience, social comparison may have led them to "gauge their expected and actual performance by comparison with that of others" (Stone, 1994, p. 453) - in this case, with other CEDS with more FiT experiences.

Social comparisons used to generate appraisals of teaching self-efficacy beliefs may be taken from "previous educational experiences, tradition, [or] the opinion of experienced practitioners" (Groccia \& Buskist, 2011, p. 5). Thus, participants in this study who lacked prior teaching experience may have initially overestimated their capability as a result of previous educational experiences. When individuals initially overestimate their abilities to perform a new task, they may not put in the time or effort needed to succeed at a given task. Tollerud (1990) suggested that those without any actual prior teaching experience may not realize the complexity of the task, the effort required, or what skills are needed to teach effectively. In the current study, this realization may be reflected in participants' initial drop in mean SETI scores from no teaching experiences to one to two teaching experiences.

The CE literature offers clues for how to buffer against this initial drop in self-efficacy. For example, $\mathrm{CE}$ teaching preparation research suggests the importance of engaging in multiple teaching experiences (Suddeath et al., 2020) with a gradual increase in responsibility (Baltrinic et al., 2016) and frequent (i.e., weekly) supervision from CE faculty supervisors, as well as feedback and support from peers (Baltrinic \& Suddeath, 2020a, 2020b; Elliot et al., 2019). These authors' findings reportedly support students' ability to normalize their initial anxiety, fears, and self-doubts; conceptualize their struggle and discomfort as a part of the developmental process; push through perceived failings; and reflect on and grow from initial teaching experiences. Elliot et al. (2019) noted specifically that supervision with peer support increased participants' (a) ability to access an optimistic mindset amidst self-doubt, (b) self-efficacy in teaching, (c) authenticity in subsequent teaching experiences, and (d) facility with integrating theory into teaching practice. Overall, the current findings add to the CE literature by suggesting CE programs increase the number of FiT experiences (to at least five, preferably) for CEDS.

Our findings also reflect similarities in CEDS' self-efficacy patterns to those of Tollerud (1990) and Olguin (2004). Similar to Tollerud and Olguin, we grouped participants according to the number of FiT experiences: no fieldwork experience, one to two experiences, three to four experiences, and five or more experiences. This study identified the same pattern in teaching self-efficacy as observed by Tollerud and Olguin, with those who reported no FiT experience indicating higher mean SETI scores than those with one to two FiT experiences and three to four FiT experiences. Although scores slightly increased from one to two FiT experiences to three to four FiT experiences, it was not until CEDS accumulated five or more FiT experiences that the mean SETI score rose above that of those with no FiT experiences. The consistency of this pattern over the span of 30 years seems to confirm the importance of providing CEDS several FiT opportunities (i.e., at least five) to strengthen their self-efficacy in teaching. Though responsibility within FiT experiences was aggregated in this study as it was in Tollerud and Olguin, research (e.g., Baltrinic et al., 2016; Orr et al., 2008) and common sense would suggest that CEDS need multiple supervised teaching opportunities with progressively greater responsibility and autonomy. However, future research is needed to examine how CEDS' selfefficacy toward teaching changes over time as they move from having no actual teaching experience, to beginning their FiT, to accruing substantial experiences with FiT. 


\section{Implications}

For many counselor educators, teaching and related responsibilities consume the greatest proportion of their time (Davis et al., 2006). As such, providing CEDS multiple supervised opportunities (Orr et al., 2008; Suddeath et al., 2020) to apply theory, knowledge, and skills in the classroom before they transition to the professoriate seems important for fostering teaching competency (Swank \& Houseknecht, 2019) and, ideally, mitigating against feelings of stress and burnout that some first-year counselor educators experience as a result of poor teaching preparation (Magnuson et al., 2006). Given the initial drop in self-efficacy toward teaching as identified in this study and the relationship between higher levels of self-efficacy and increased student engagement (Gibson \& Dembo, 1984) and learning outcomes (Goddard et al., 2000), greater job satisfaction, reduced stress and emotional exhaustion (Klassen \& Chiu, 2010; Skaalvik \& Skaalvik, 2014), and flexibility and persistence during perceived setbacks in the classroom (Elliot et al., 2019), several suggestions are offered.

Although it is an option in many CE doctoral programs, some CEDS may graduate without any significant FiT experiences (Barrio Minton \& Price, 2015; Hunt \& Weber Gilmore, 2011; Suddeath et al., 2020). Although not all CEDS want to go into the professoriate, for those interested in working in academia, it is our hope that programs will provide students with multiple - and preferably at least five-developmentally structured supervised teaching opportunities. Whether these are formal curricular FiT experiences such as teaching practicums and internships or informal co-curricular coteaching or IOR experiences (and likely a combination of the two), CE literature suggests that these experiences should include frequent and ongoing supervision (Baltrinic \& Suddeath, 2020a) and progress from lesser to greater responsibility and autonomy within the teaching role (Baltrinic et al., 2016; Hall \& Hulse, 2010; Orr et al., 2008). These recommendations for the structuring of FiT are important given the incredible variation in this aspect of training (e.g., Orr et al., 2008; Suddeath et al., 2020) and the consistency in the observed pattern of self-efficacy toward teaching and the number of FiT experiences (Olguin, 2004; Tollerud, 1990).

To help buffer against the initial drop in self-efficacy toward teaching scores from zero to one to two teaching experiences in this study and previous research (Olguin, 2004; Tollerud, 1990), research emphasizes the importance of increased oversight and support of CEDS before and during their first teaching experiences (Baltrinic \& Suddeath, 2020a; Elliot et al., 2019; Stone, 1994). CE faculty members who teach coursework in college teaching, are instructors for teaching internships, and/or are providing supervision of teaching for FiT experiences should normalize initial anxiety and self-doubt (Baltrinic \& Suddeath, 2020a; Elliot et al., 2019) and encourage realistic expectations for students' first teaching experiences (Stone, 1994). Stone (1994) suggested that fostering realistic expectations in those engaging in a new task may actually "increase effort, attention to strategy, and performance by increasing the perceived challenge of tasks" (p. 459). This was evident in Elliot et al.'s (2019) study in which CEDS reframed the initial struggles with teaching experiences as opportunities for growth and development. On the other hand, individuals who overestimate or strongly underestimate selfefficacy may not put in the time or effort needed to succeed at a given task. For example, those who overestimate their capabilities may not increase their effort, as they already believe they are going to perform well (Stone, 1994). Similarly, those who underestimate their ability may not increase effort or give sufficient attention to strategy, as they perceive that doing so would not improve their performance anyway. These findings support the need for CE programs to provide oversight and support and engender realistic expectations before or during students' first FiT experiences. 


\section{Limitations and Future Research}

Limitations existed related to the sample and survey. Representativeness of the sample, and thus generalizability of findings, is limited by the voluntary nature of the study (i.e., self-selection), crosssectional design (i.e., tracking efficacy beliefs over time), and solicitation of participants via CESNET-L (i.e., potential for CEDS to miss the invitation to participate) and doctoral program liaisons (i.e., unclear how many forwarded the invitation). Another limitation relates to the variability in participants' FiT experiences, such as the assigned role and responsibility within FiT, frequency and quality of supervision, and whether and how experiences were developmentally structured. Additionally, self-report measures were used, which are prone to issues of self-knowledge (e.g., over- or underestimation of capability with self-efficacy, accurate recall of FiT experiences) and social desirability.

Future research could utilize qualitative methods to investigate what components of FiT experiences (e.g., quality, type of responsibility) prove most helpful in strengthening CEDS' self-efficacy and how it changes with increased experience. Given the limitations of self-efficacy, researchers could also investigate other outcomes (e.g., test scores, student evaluations) instead of or alongside self-efficacy. Although this study identified the importance of acquiring at least five FiT experiences for strengthening SETI scores, little is known about how to developmentally structure FiT experiences so as to best strengthen self-efficacy toward teaching. Researchers could use quantitative approaches to investigate the relationship between various aspects of CEDS' FiT experiences (e.g., level of responsibility and role, frequency and quality of supervision) and SETI scores. Researchers could also develop a comprehensive model for providing FiT that includes recommendations as supported by CE research (e.g., Baltrinic et al., 2016; Baltrinic \& Suddeath, 2020a, 2020b; Elliot et al., 2019; Orr et al., 2008; Suddeath et al., 2020; Swank \& Houseknecht, 2019). Finally, instead of investigating FiT experiences of CEDS and their impact on teaching self-efficacy, future research could investigate first-year counselor educators to determine if and how their experience differs.

\section{Conclusion}

Investigating teaching preparation practices within CE doctoral programs is essential for understanding and improving training for future counselor educators. Although research already supports the inclusion of multiple supervised teaching experiences within CE doctoral programs (Suddeath et al., 2020), the results of this study provide greater clarity to the differential impact of FiT experiences on CEDS' teaching self-efficacy. Given the consistently observed pattern of teaching self-efficacy and FiT experiences from this and other studies over the last 30 years, doctoral training programs should thoughtfully consider how to support students through their first FiT experiences, and ideally, offer students multiple opportunities to teach.

\section{Conflict of Interest and Funding Disclosure}

The authors reported no conflict of interest or funding contributions for the development of this manuscript. 


\section{References}

Association for Counselor Education and Supervision. (2016). Best practices in teaching in counselor education report. https://acesonline.net/wp-content/uploads/2018/11/ACES-Teaching-Initiative-Taskforce-FinalReport-2016.pdf

Baltrinic, E. R., Jencius, M., \& McGlothlin, J. (2016). Coteaching in counselor education: Preparing doctoral students for future teaching. Counselor Education and Supervision, 55(1), 31-45. https://doi.org/10.1002/ceas.12031

Baltrinic, E. R., Moate, R. M., Hinkle, M. G., Jencius, M., Taylor, J. Z. (2018). Counselor educators' teaching mentorship styles: A Q methodology study. The Professional Counselor, 8(1), 46-59. https://doi.org/10.15241/erb.8.1.46

Baltrinic, E. R., \& Suddeath, E. (2020a). Counselor education doctoral students' lived experiences with supervision of teaching. Counselor Education and Supervision, 59(3), 231-248. https://doi.org/10.1002/ceas.12186

Baltrinic, E. R., \& Suddeath, E. G. (2020b). A Q methodology study of a doctoral counselor education teaching instruction course. The Professional Counselor, 10(4), 472-487. https://doi.org/10.15241/erb.10.4.472

Bandura, A. (1997). Self-efficacy: The exercise of control. Freeman.

Barrio Minton, C. A. (2020). Signature pedagogies: Doctoral-level teaching preparation. Teaching and Supervision in Counseling, 2(2), 39-46. https://doi.org/10.7290/tsc020205

Barrio Minton, C. A., \& Price, E. (2015, October). Teaching the teacher: An analysis of teaching preparation in counselor education doctoral programs. Presentation session presented at the meeting of the Association for Counselor Education and Supervision Biannual Conference, Philadelphia, PA.

Cohen, J. (1992). A power primer. Psychological Bulletin, 112(1), 155-159. https://doi.org/10.1037/0033-2909.112.1.155

Creswell, J. W., \& Guetterman, T. C. (2019). Educational research: Planning, conducting, and evaluating quantitative and qualitative research (6th ed.). Pearson.

Davis, T. E., Levitt, D. H., McGlothlin, J. M., \& Hill, N. R. (2006). Perceived expectations related to promotion and tenure: A national survey of CACREP program liaisons. Counselor Education and Supervision, 46(2), 146-156. https://doi.org/10.1002/j.1556-6978.2006.tb00019.x

Elliot, A., Salazar, B. M., Dennis, B. L., Bohecker, L., Nielson, T., LaMantia, K., \& Kleist, D. M. (2019). Pedagogical perspectives on counselor education: An autoethnographic experience of doctoral student development. The Qualitative Report, 24(4), 648-666. https://doi.org/10.46743/2160-3715/2019.3714

Gibson, S., \& Dembo, M. H. (1984). Teacher efficacy: A construct validation. Journal of Educational Psychology, 76(4), 569-582. https://doi.org/10.1037/0022-0663.76.4.569

Goddard, R. D., Hoy, W. K., \& Hoy, A. W. (2000). Collective teacher efficacy: Its meaning, measure, and impact on student achievement. American Educational Research Journal, 37(2), 479-507. https://doi.org/10.2307/1163531

Groccia, J. E., \& Buskist, W. (2011). Need for evidence-based teaching. New Directions for Teaching and Learning, 2011(128), 5-11. https://doi.org/10.1002/tl.463

Hall, S. F., \& Hulse, D. (2010). Perceptions of doctoral level teaching preparation in counselor education. The Journal of Counselor Preparation and Supervision, 1(2), 2-15. https://core.ac.uk/download/pdf/234957931.pdf

Haynes, S. N., Richard, D. C. S., \& Kubany, E. S. (1995). Content validity in psychological assessment: A functional approach to concepts and methods. Psychological Assessment, 7(3), 238-247. https://doi.org/10.1037/1040-3590.7.3.238

Hebbani, A., \& Hendrix, K. G. (2014). Capturing the experiences of international teaching assistants in the US American classroom. New Directions for Teaching and Learning, 2014(138), 61-72. https://doi.org/10.1002/t1.20097

Hunt, B., \& Weber Gilmore, G. (2011). Learning to teach: Teaching internships in counselor education and supervision. The Professional Counselor, 1(2), 143-151. https://doi.org/10.15241/bhh.1.2.143

Klassen, R. M. \& Chiu, M. M. (2010). Effects on teachers' self-efficacy and job satisfaction: Teacher gender, years of experience, and job stress. Journal of Educational Psychology, 102(3), 741-756.

https://doi.org/10.1037/a0019237 
Limberg, D., Bell, H., Super, J. T., Jacobson, L., Fox, J., DePue, M. K., Christmas, C., Young, M. E., \& Lambie, G. W. (2013). Professional identity development of counselor education doctoral students: A qualitative investigation. The Professional Counselor, 3(1), 40-53. https://doi.org/10.15241/dll.3.1.40

Magnuson, S., Black, L. L., \& Lahman, M. K. E. (2006). The 2000 cohort of new assistant professors of counselor education: Year 3. Counselor Education and Supervision, 45(3), 162-179. https://doi.org/10.1002/j.1556-6978.2006.tb00140.x

Magnuson, S., Shaw, H., Tubin, B., \& Norem, K. (2004). Assistant professors of counselor education: First and second year experiences. Journal of Professional Counseling: Practice, Theory, and Research, 32(1), 3-18. https://doi.org/10.1080/15566382.2004.12033797

Moore, A. (2019). Counselor education and supervision doctoral students' experiences as instructors of record teaching a master's level counseling course: A descriptive phenomenological investigation [Doctoral dissertation, Kent State University]. OhioLINK. http://rave.ohiolink.edu/etdc/view?acc num=kent1573225509664446

Olguin, D. L. C. (2004). Determinants of preparation through perceptions of counseling and teaching self-efficacy among prospective counselor educators [Doctoral dissertation, University of New Orleans]. ProQuest.

Orr, J. J., Hall, S. F., \& Hulse-Killacky, D. (2008). A model for collaborative teaching teams in counselor education. Counselor Education and Supervision, 47(3), 146-163. https://doi.org/10.1002/j.1556-6978.2008.tb00046.x

Prieto, L. R., Yamokoski, C. A., \& Meyers, S. A. (2007). Teaching assistant training and supervision: An examination of optimal delivery modes and skill emphases. Journal of Faculty Development, 21(1), $33-43$.

Richardson, R., \& Miller, D. (2011). Predicting the use of learner-centered instructional methods by undergraduate social work faculty. Journal of Baccalaureate Social Work, 16(2), 115-130. https://doi.org/10.18084/basw.16.2.v17824840x8v1301

Skaalvik, E. M., \& Skaalvik, S. (2014). Teacher self-efficacy and perceived autonomy: Relations with teacher engagement, job satisfaction, and emotional exhaustion. Psychological Reports, 114(1), 68-77. https://doi.org/10.2466/14.02.pr0.114k14w0

Stone, D. N. (1994). Overconfidence in initial self-efficacy judgments: Effects on decision processes and performance. Organizational Behavior and Human Decision Processes, 59(3), 452-474. https://doi.org/10.1006/obhd.1994.1069

Suddeath, E., Baltrinic, E., \& Dugger, S. (2020). The impact of teaching preparation practices on self-efficacy toward teaching. Counselor Education and Supervision, 59(1), 59-73. https://doi.org/10.1002/ceas.12166

Swank, J. M., \& Houseknecht, A. (2019). Teaching competencies in counselor education: A Delphi study. Counselor Education and Supervision, 58(3), 162-176. https://doi.org/10.1002/ceas.12148

Tollerud, T. R. (1990). The perceived self-efficacy of teaching skills of advanced doctoral students and graduates from counselor education programs [Doctoral dissertation, University of Iowa]. ProQuest.

Tschannen-Moran, M., Hoy, A. W., \& Hoy, W. K. (1998). Teacher efficacy: Its meaning and measure. Review of Educational Research, 68(2), 202-248. https://doi.org/10.3102/00346543068002202

Waalkes, P. L., Benshoff, J. M., Stickl, J., Swindle, P. J., \& Umstead, L. K. (2018). Structure, impact, and deficiencies of beginning counselor educators' doctoral teaching preparation. Counselor Education and Supervision, 57(1), 66-80. https://doi.org/10.1002/ceas.12094 